\title{
Analysis of Six-Phase Transmission Lines for Increasing Power
}

\author{
Abhishek Kumar \\ M. Tech. Scholar \\ Ram Krishna Dharmarth Foundation \\ College of Engineering \\ Bhopal, M.P, India
}

akumar.kumar369@gmail.com

\author{
Pramod Kumar Rathore \\ Assistant Professor \\ Ram Krishna Dharmarth \\ Foundation University College of \\ Engineering \\ Bhopal, M.P, India \\ pkrathore23@gmail.com
}

\author{
Dr. Ashok Kumar Jhala \\ Professor \\ Ram Krishna Dharmarth \\ Foundation University College \\ of Engineering \\ Bhopal, M.P, India \\ akjhala.35@gmail.com
}

\begin{abstract}
In the India, especially in metropolitan areas, transmission infrastructure is congested due to a combination of increasing load demands, declining investment, and aging facilities. It is anticipated that significant investments will be required for new construction and upgrades in order to serve load demands. This paper explores higher phase order systems, specifically, six-phase, as a means of increasing power transfer capability, and provides a comparison with conventional three-phase double circuit transmission lines. Line parameters calculations performed in this thesis show that line impedances in six-phase lines have a slight difference, compared to three-phase double circuit line. The electric and magnetic fields calculations show that, ground level electric fields of the six-phase lines decline more rapidly as the distance from center of the lines increase. The six-phase lines have a better performance on ground level magnetic field. Based on the electric and magnetic field results, right of way requirements for the six-phase lines and three-phase double circuit line were calculated. The calculation results of right of way show that six-phase lines provide higher power transfer capability with a given right of way.
\end{abstract}

Keywords: Six Phase, Transmission, Matlab, High Phase

\section{INTRODUCTION}

In India, some states and regions have high demand load growth, due to the growth of the economy and the population. According to statistics the annual load demand growth rate for customers was approximately $5.3 \%$ in the last 20 years, and the estimated annual load demand growth rate will be $5 \%$ in the next 20 years. The projected load growth rates in these areas are higher than the national average rate of $1.1 \%$.

The high load demand growth requires more power transfer capability of the existing transmission infrastructure. Considering the lengthy process of transmission line construction, investment on transmission grid should be made for the long term .In contrast to the continuing load demand growth and congestion, investments on new transmission facilities in the India declined more than $44 \%$ over the past 25 years. The most common approach to increase power transfer capability is in-creasing system voltage. Some factors responsible for this are listed below.

- Social concerns about the impact of transmission lines.

- Laws and standards issued by governments and organizations.

- Cost of the transmission line corridor

\section{High PHASE ORDER TECHNOLOGY AND RESEARCH REVIEWS}

A. High phase order transmission introduction and history

The idea of high phase order transmission was first introduced in 1973, by H. C. Barnes and L. O. Barthold [11]. The purpose of high phase order system was to convert the original three-phase power into six, nine, and twelve phase power. For the same phase-to-ground voltage, high phase order systems have lower phase-tophase voltages, compared to a three-phase system. The phasors of three-phase and high phase order systems are shown in Fig. 


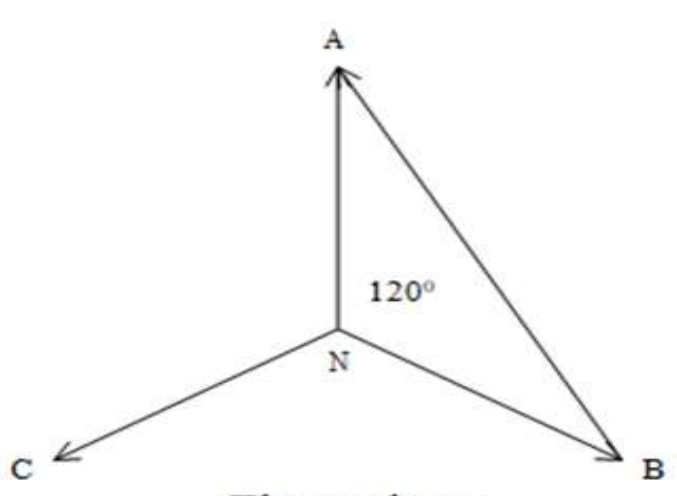

Three-phase

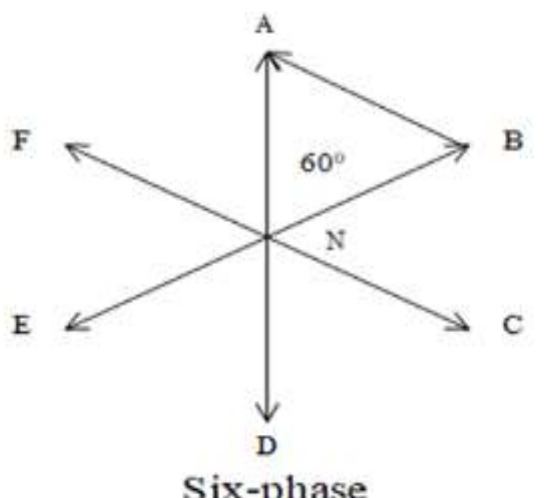

Fig.1 Three-phase and six-phase order phasors.

$V_{\lg 3 \varphi}=V_{\lg 6 \varphi}=V_{\lg 12 \varphi}$

$V_{l l} 3 \varphi=\sqrt{ } 3 V_{l l 6 \varphi}=3 V_{l l 12 \varphi}$

High phase order and three-phase conversion

As described above, higher phase order transmission lines are used to con- vert three-phase power to higher phase order power for delivery. It does not re- quire high phase order generators to provide high phase power. It suggests that the high phase order transmission lines must be interconnected with the existing three-phase system. The function of three/HPO phase converter block is to achieve correct phase-shifting between the three-phase and the high phase order system. Present techniques for phase-shifting from three-phase to higher phase can be classified into two categories:

\section{(1) Transformer}

(2) Power electronic device.

\section{(1) Transformer based phase-shifting}

Phase-shifting transformer techniques are based on electromagnetic coupling between transformer windings. Phase-shifting from three-phase to $\mathrm{N}$ phase order voltage, is achieved by different wiring connection of transformer windings. This technique has been studied and implemented for many years and different wiring connection methods were proposed and designed. Many wiring connections required that transformer manufacturers abandon the conventional three-phase transformer structures and design new transformer structures for the three-phase to N-phase transformers. This requirement not only increased the cost of transformers, but also made the transformers difficult to be modeled in the existing commercial power area analysis and simulation software. Thus, many proposed transformer connections were not widely accepted by the industry.

\section{(2) Power electronic devices}

The power electronic devices can be used to achieve phase-shifting for high phase order transmission line. AC-AC converter with IGBT, thyristor, and symmetrically phase shifted carriers has been designed and presented. Although the AC-AC converter is not originally designed for high phase order application, it does have the ability to achieve the phase-shifting for three-phase and high phase order voltage conversion. Compared to the transformer based phase shift techniques, power electronic devices are more expensive and complicated.

\section{B. High phase order tower configuration}

The benefits of high phase order systems arise from the smaller phase angles between phases. As phase-to-phase voltage decreases, high phase order transmission lines generate lower conductor surface gradients and noise levels. This results in smaller space between phases. Some compact tower configurations were designed for high phase order transmission lines. Additionally, some three-phase double circuit line towers can also be employed in six-phase order transmission lines. 


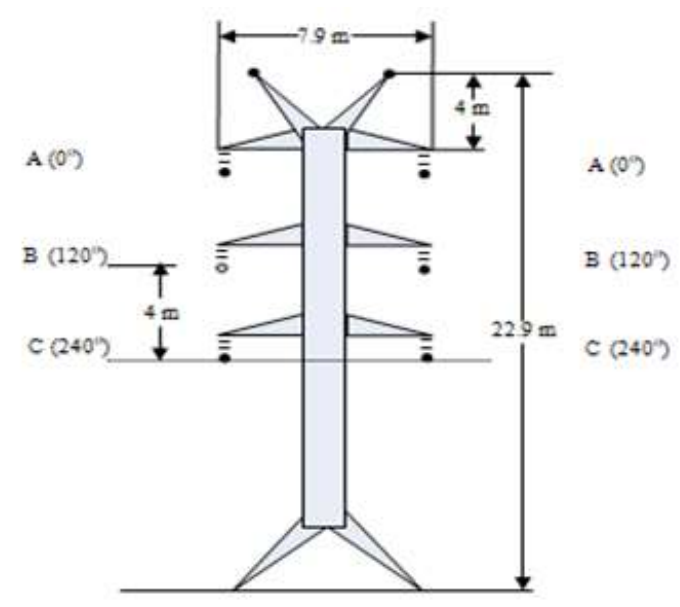

(1). $132 \mathrm{kV}$ three-phase double circuit conventional tower line

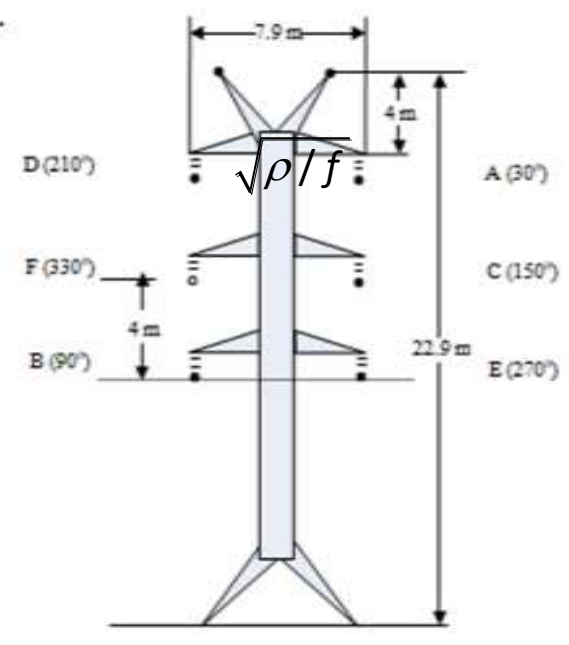

(2). $66 \mathrm{kV}$ six-phase conventional tower transmission line

Fig.2 Three-phase and six-phase tower configuration and phase arrangements.

\section{TRANSmission Line PARAMETERS}

The power transfer capability of transmission lines can be evaluated by surge impedance loading, steady-state stability limit, thermal limit, and maximum power flow. The thermal limit depends on environmental factors, such as solid condition, wind speed, and temperature. Additionally, surge impedance loading, steady-state stability limit, and maximum power flow are all dependent on surge impedance, and system operation status. To calculate surge impedance loading, the following line parameters will be calculated in this chapter: (1) Self and mutual impedance; (2) Capacitance; (3) Surge impedance. The transmission lines will be assumed to be completely transposed.

\section{(1)Transmission lines impedance}

Transmission line impedance depends on many factors, such as, transmission line conductors, solid condition, temperature, and frequency ("skin effect") . It is assumed that all these factors are equal in the calculations. The impedance calculation process for a three-phase single circuit line with horizontal configuration will be introduced in this section, and the same process will be extended to calculate the four case. To consider the effect of return current caused by earth, the earth return effects can be replaced by sets of earth return (image) conductors located under the transmission line conductors. The distances of the earth return conductors from their overhead conductors are calculated by,

$H_{n}=658.5 \sqrt{\frac{\rho}{f}}$

where $\rho$ is the earth resistivity and $f$ is the frequency in Hz.

\section{(2) Transmission lines capacitance}

The transmission line capacitance calculation can be derived by a three-phase single circuit line with a horizontal configuration. The tower configuration is shown in Fig. 3. When the transmission line is energized, negative charges are induced on the ground. To replace the earth return effects, image conductors were also introduced. The depth of image conductor is equal to the height of the overhead conductors: $h_{n}=H_{N}$. The surge impedance and surge impedance loading are calculated based on the $\pi$ model of a lossless line shown.

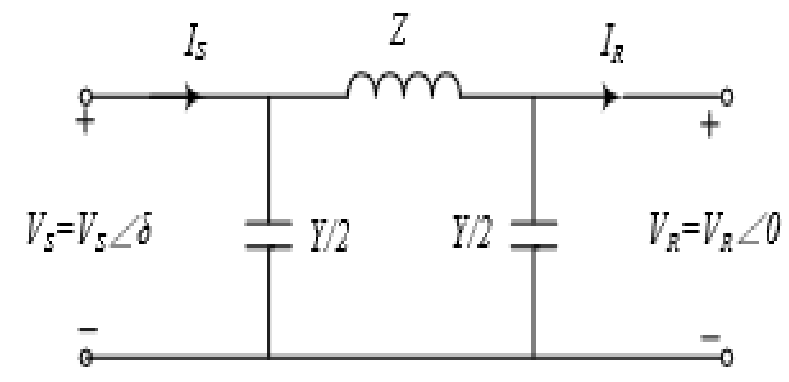

Fig. 3 Equivalent $\pi$ circuit for a lossless line 


\section{(c)Surge impedence loading}

The surge impedance of six-phase transmission line with compact tower is about $15 \%$ less than the transmission line conventional tower. As a consequence, surge impedance loading of six-phase compact tower transmission line is about $18 \%$ higher than the threephase double circuit transmission line. Due to the increase of phase-to-ground voltage in the $132 \mathrm{kV}$ sixphase conventional tower case, surge impedance loading of the transmission line is about $297 \%$ of the three-phase double circuit transmission line with the same tower configuration.

\section{Electric And Magnetic Field Calculations}

Electric and magnetic field are significant in the overall design of transmission line. Electric and magnetic field strengths of transmission line directly determine many other criteria of transmission lines; such as corona, communication interference and audible noise. Electric and magnetic field distributions at ground level are compared and evaluated in this chapter.

\section{A. Electric field distribution at ground level}

The transmission line electric field at ground is determined by superposition of electric field generated by all conductors. The calculation procedure is explained as below.The electric field, generated by conductor $\mathrm{k}$, at point $\mathrm{x}$ is shown in Fig. To consider earth return effects, an image conductor is introduced and the charges of the image conductor are the negative values of its overhead charges.

$$
\varepsilon_{0}=\frac{10^{-9}}{36 \pi} \mathrm{F} / \mathrm{m}
$$

The electric field distribution can be plotted based on the calculation of electric field at each point of ground level. The electric field calculation procedure can be extended to the three-phase double circuit line and six-phase transmission lines proposed above

Table 1. Summary of Electric Field Calculation at Ground Level

\begin{tabular}{|l|l|l|}
\hline Case name & $\begin{array}{l}\text { Maximum } \\
\text { electric } \\
\text { field }(\mathrm{kv} / \mathrm{m})\end{array}$ & $\begin{array}{l}\text { Electric field at } \\
\text { edge of } \\
\mathrm{ROW}(\mathrm{kv} / \mathrm{m})\end{array}$ \\
\hline $\begin{array}{l}132 \mathrm{kv} \text { 3-ph double circuit } \\
\text { conventional tower line }\end{array}$ & 0.1 & 0.03 \\
\hline $66 \mathrm{kv}$ 6-ph conventional tower & 0.2 & 0.01 \\
\hline
\end{tabular}

www.ijoscience.com

\begin{tabular}{|l|l|l|}
\hline line & & \\
\hline $66 \mathrm{kv}$ 6-ph compact tower line & 0.1 & 0.01 \\
\hline $\begin{array}{l}132 \mathrm{kv} \text { 6-ph conventional tower } \\
\text { line }\end{array}$ & 0.2 & 0.04 \\
\hline
\end{tabular}

\section{B. Magnetic field distribution at ground level}

Concerns about magnetic field are mainly due to possible biological effects. The potential hazards to human health from transmission lines have been investigated for years. Although there is no definite conclusion about the concern caused by magnetic field, many organizations and states have published some requirements and laws about magnetic field limitations. In this thesis, the magnetic field distribution at ground level are evaluated and compared. Magnetic field is generated by the currents through conductors. The calculation procedures of magnetic field are described below.

The magnetic field strength at point $x$, generated by conductor $\mathrm{k}$, can be calculated by,

$$
H_{k}(\mathrm{x})=\frac{I_{k}}{2 \pi d_{k_{x}}}
$$

The magnetic field distributions of the proposed scenarios are plotted in Figs. In this, $46 \mathrm{~m}$ (150 ft) was selected as right of way of the cases. As shown by the results, magnetic field under six-phase transmission lines is lower than the value under three-phase line. This is due to effective canceling out of magnetic field generated by six-phase transmission lines. Magnetic field decreases when six-phase transmission line tower is compacted. The result is that magnetic field under the 66 $\mathrm{kV}$ six-phase conventional tower transmission line is higher than the values under the line with compact tower.

\section{TRANSMISSION LINE RIGHT OF WAY CAlculation}

Right of way is significant in both transmission line design and construction cost. From the utilities viewpoint, the most important priority of right of way is preservation of its assets security with a satisfactory level. For the public concentration, appropriated right of way is to eliminate risk to human and property from transmission line electric and magnetic field. Potential hazards of electric and magnetic field to human health 
from living or working have been investigated for years. Although no definite conclusion has been drawn on the harms of electric and magnetic field to human beings, many states and organizations still published codes and standards to regulate transmission line electric and magnetic field at ground level. In this section, electric and magnetic field generated by the three-phase double circuit line within selected right of way, was calculated. The right of way for the six-phase lines to achieve the same field strengths was calculated and evaluated. Transmission line right of way width calculation procedures are described as below: As shown below, transmission line right of way can be calculated by,

$$
R O W=2(A+B+C)
$$

Where

$\mathrm{A}=$ Horizontal clearance to buildings

$\mathrm{B}=$ Conductor blowout due to angle $\left(120 \mathrm{~F}^{\circ} \mathrm{sag}\right)$

$\mathrm{C}=$ Distance from centerline of tower structure to outside conductor at- attachment point

In the horizontal clearance to buildings is determined by electric and magnetic field distributions at ground level, and also dependent on IEEE and state laws requirements. Conductor blowout is determined by wind force and conductor weight. In this thesis, the same transmission line environmental conditions and conductor types was assumed in the calculations. The references levels above are defined for all transmission line voltage levels. Due to the relatively low voltage level of the proposed cases $(132 \mathrm{kV})$, the ground level electric and magnetic field do not exceed the public safety requirements for right of way. For a better demonstration purpose, $46 \mathrm{~m}$ (150 ft) right of way was selected for the three-phase double circuit transmission line. The ground level electric and magnetic field at the edge of right of way, generated by $132 \mathrm{kV}$ three- phase double circuit line, was calculated and set as the criteria in this thesis. The right of way requirements for the six-phase transmission lines were calculated to achieve the same ground level electric and magnetic field strength at the edge of right of way. To calculate the right of way of the proposed cases, standard suspension insulators were selected as transmission line insulator type. According to reference, number of standard insulators units at moderate pollution level for a $132 \mathrm{kV}$ vertical insulator string is with the same tower configuration, voltage level, electric and magnetic field strength at edge of right of way, the $66 \mathrm{kV}$ six-phase transmission line requires about $18 \%$ less right of way. With compact tower configuration, the six-phase transmission line requires $36 \%$ less right of way and provides $19 \%$ more power transfer capability. With higher phase-to-ground voltage level and the same tower configuration, $132 \mathrm{kV}$ six-phase transmission line requires only $8 \%$ more right of way, compared to 132 $\mathrm{kV}$ three-phase double circuit lines; while six-phase line power transfer capability increases by $193 \%$. It demonstrates that the tower size and right of way requirements of six-phase transmission lines can be significantly compacted, while the power transfer capability can stay the same as double circuit three-phase line. In another words, six-phase line provides more power transfer capability with the same tower size and right of way requirements as three-phase double circuit line.

\section{SiX-Phase Fault Analysis}

There are 120 fault combinations and 23 unique fault types in a six-phase system, due to phase angle change and phase increase. There are only 5 fault types in threephase system. For this reason, high phase order protection is much more complicated than three-phase system. Although research and field experiences have been accumulated for high phase order fault analysis and protection, it is unclear that exiting technology provides adequate protection for high phase order transmission. To clarify this problem, six-phase fault analysis and sixphase transmission line protection system design are presented in this chapter and the following chapter, respectively.

\section{A. Six-phase equivalent system}

Many theories and research about high phase order fault analysis have been published. The major high phase order fault analysis methods are based on symmetrical components method and phase coordinated method.As shown the system containing six-phase transmission line is a three-phase and six-phase mixed system. For transmission line protection design purpose, beside the transmission line, the rest of the system can be simplified into two equivalent impedance components and two ideal sources. Two ideal three-phase voltage sources provide power at both sides of the six-phase transmission line. Two three-phase equivalent impedances are connected between the ideal sources and the six-phase transmission line. Ideal transformers are connected 
between the equivalent impedance and six-phase transmission line to achieve phase-shifting.

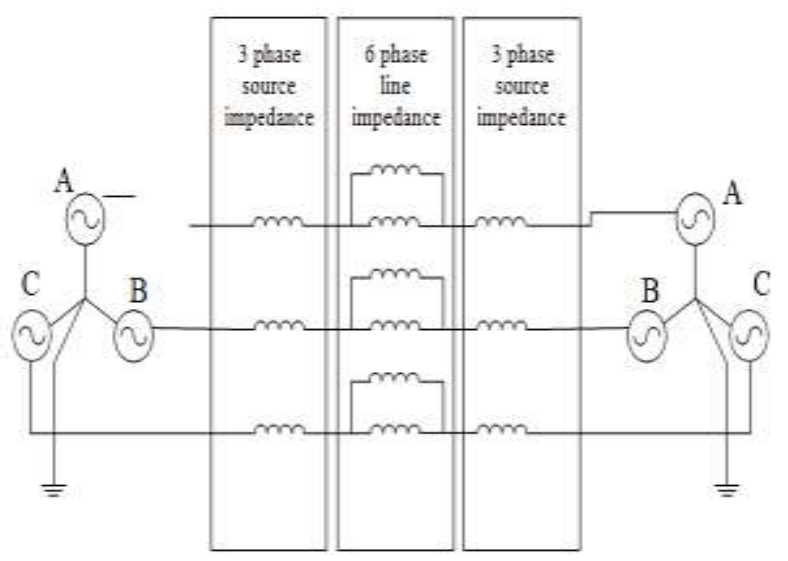

Fig. 4 Three-phase simplified system with six-phase transmission line network.

\section{B. Fault analysis cases}

In this section, three systems were selected and upgraded into six-phase transmission lines. Six-phase fault analysis was studied on the upgraded transmission lines. A program developed using MATLAB code was used to calculate the equivalent impedance and fault currents. Additionally, upgraded transmission lines were reconfigured into three-phase double circuit lines in the systems. For both three-phase double circuit lines and six-phase transmission lines, it was assumed that same tower configuration, phase-to-ground voltage, and transmission line length were employed. Three-phase fault analysis was studied in the three-phase double circuit line.

\section{Immunity from mutual coupling effects}

Fault phase selective for all types of single and multiple faultsThe operation of segregated phase comparison system is described for an internal and an external transmission line faults. As shown in Figs. 6.1 and 6.2, once a fault occurs in the system and phase current exceeds the threshold value, positive trip signal is set to 1 ( if the fault occurs in a positive cycle) and sent to the opposite end relay. The remote trip signal is compared to the local relay trip signal. If both signals are equal, it means the currents at both ends are flowing into the transmission line, and the faults location is in the transmission line. Both relays trip the line immediately. If the signals from both ends are not equal, the result indicates that the high phase current is due to the faults outside the transmission line. Then, the relays will not trip the line. More details of segregated phase comparison scheme are available in reference.

\section{Current differential relay}

Current differential relay was originally developed for transformer and generator protection, and successfully extended to transmission line protection. With increasing applications of digital communicational channel, the interest on current differential relay is greater than before. Compared to other relays, current differential relay has many advantages. The simplicity of the scheme and setting is a one of the most significant advantages. Generally, the $50 \%$ setting rule is applied for simplicity. Thus, restraint characteristic is commonly set to $50 \%$. The curve slope is $\mathrm{k}=1$. Additionally, a pick-up setting of $50 \%$ of minimum fault current was recommended. With relay settings calculated above, the segregate phase comparison protection system will start to compare the phase currents when the transmission line phase current is over $135 \mathrm{~A}$ at the primary side. Current differential relays generally recommend a pick-up setting of $50 \%$ of minimum fault current. The fault current is the sum of the currents from the both ends of the line.

In Fig.5, conductor and phase arrangements of threephase double circuit and six phase line are shown,

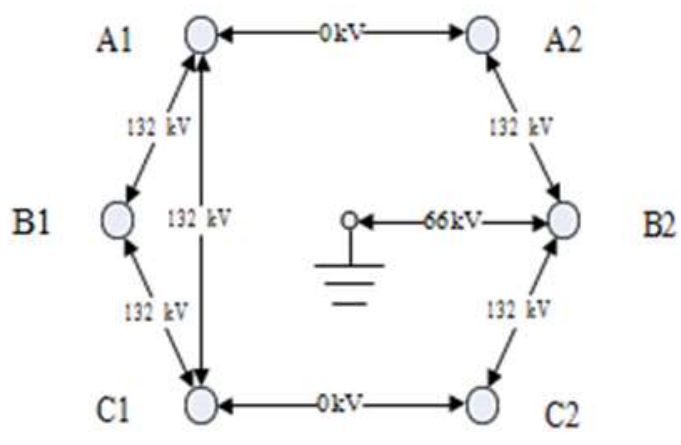

(a) Three-phase double circuit line 


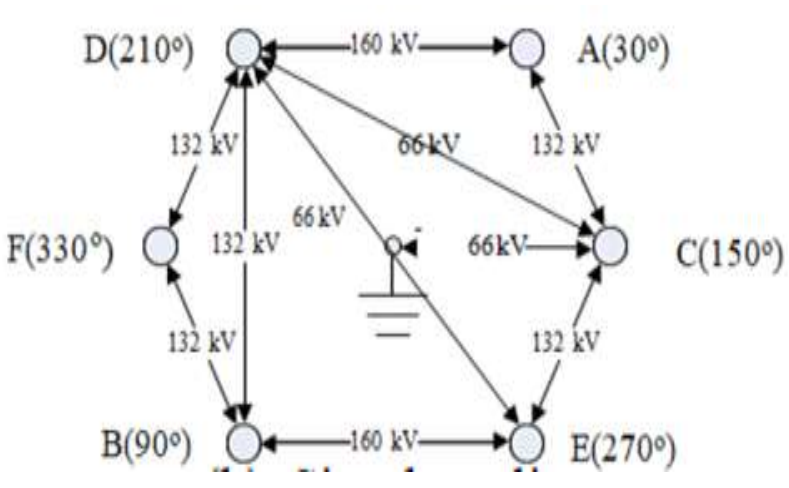

(b) Six-phase line

Fig.5 Conductor and phase arrangements of three-phase double circuit and six-phase line.

As shown in Fig. 5, the conductors in the six-phase transmission line can be classified into two groups: (1) A-C-E and (2) D-F-B. These two groups are similar as the groups in the three-phase double circuit line. The only difference is that the phase in two groups is not equal as that in the three-phase double circuit line. This difference does not influence the six-phase protection design.

\section{CONCLUSION}

The research objective work is evaluating and comparing the advantages of three-phase double circuit and sixphase transmission line. For evaluation and comparison, four transmission line cases, one three-phase double circuit, and three different six-phase transmission lines, were selected. Transmission line parameters, power transfer capability, electric field, magnetic field, and right of way, were selected as evaluation criteria. A program developed using MATLAB code, was used to calculate performances of the four proposed cases on the selected criteria. Additionally, to clarify the doubts about six-phase transmission line protection, fault analysis on three-phase double circuit line, and six-phase transmission line, were studied in three systems.

\section{REFERENCES}

[1] M. Willrich, "Electricity transmission policy for America: enabling a smart grid, end-to-end," MIT-IPC-Energy Innovation Working Paper, Jul. 2009.

[2] M. W. Chupka, R. Earle, P. Fox-Penner, R. Hledik, "Transforming America's power industry: The Investment Challenge 2010 - 2030," Nov. 2008.

[3] U.S. Energy Information Administration, "Annual energy outlook 2011 with projections to 2035," May 2010.

[4] American Transmission Company, "Planning factors expansion drivers," Sep. 2011.
[5] Economic Development Research Group, Inc. "Failure to act the economic impact of current investment trends in electricity infrastructure," 2010.

[6] Harris Williams \& Co., "Transmission \& distribution infrastructure," summer, 2010.

[7] Public service commission of Wisconsin, "Environmental impact of transmission lines," Jun. 2011.

[8] F. Wagner, P. J. Schaumberg, "Power to the people: electric transmission sitting on public lands," Mar. 2009.

[9] Teshmont Consultants LP; "Taltson transmission expansion project transmission alternatives study final report," Nov. 2008.

[10] K. Dave, N. Mohan, X. Deng, R. Gorur, R. Olsen, "Analyzing techniques for increasing power transfer in the Electric Grid," accepted by North American Power Symposium 2012.

[11] H. C. Barnes, L. O. Barthold, "High phase order power transmission," CIGRE SC 32, Electra, pp. 139-153. no. 24, 1973.

[12] T. F. Dorazio, "High phase order transmission," Proceedings of Southern Tier Technical Conference, pp. 31-36, Apr. 1990. 